\title{
La función de la narrativa en la ciencia y en la investigación pedagógica*
}

\author{
José Duván Marín Gallego**
}

Recibido: 28 de julio de 2011 Revisado: 30 de agosto de 2011 Aprobado: 24 de octubre de 2011

\section{Resumen}

El presente paper es producto de investigación en el curso de Posdoctorado en Ciencia y Narrativa, dentro del convenio entre la Universidad de Córdoba (Argentina) y la Universidad Santo Tomás de Bogotá (Colombia). Se propone indagar, en primer lugar, el papel que cumple la narrativa en las teorías de la ciencia, especialmente en la física, pero también en la construcción de las ciencias sociales y humanas; y en segundo lugar, si la investigación en educación y pedagogía puede hacer uso de la narrativa, entendida como un género literario, que le va a permitir la construcción de conocimientos con validez científica y como estrategia didáctica en los procesos de enseñanza-aprendizaje para el maestro.

\section{Palabras clave}

verdad, verosímil, narrativa, relato, ciencia, investigación, pedagogía, ficción.

* El presente artículo de reflexión es producto de la investigación en el curso de Posdoctorado en Ciencia y Narrativa, dentro del convenio entre la Universidad de Córdoba (Argentina) y la Universidad Santo Tomás de Bogotá (Colombia).

** Doctor en Educación, Newport University (Los Ángeles Ca, USA). Magíster en Evaluación de la Educación (Universidad Santo Tomás, Bogotá). Especialista en Docencia Universitaria (Universidad Santo Tomás, Bogotá). Abogado (Universidad Gran Colombia, Bogotá). Licenciado en Filosofía (Universidad San Buenaventura, Bogotá). Docente investigador y Coordinador de línea de Currículo y Evaluación del Doctorado en Educación de la Universidad Santo Tomás, Bogotá. 


\title{
The role of narrative in science and in the pedagogy research
}

\author{
José Duván Marín Gallego*
}

\begin{abstract}
This present paper is a product of investigation in Postdoctoral course in Science and Narrative, inside the agreement between the University of Cordoba (Argentina) and the Saint Thomas University of Bogota (Colombia). It intend, firstly, to investigate the paper that fulfills the narrative in the theories of the science, specially, in the physics, but also in the construction of the social and human sciences, and secondly, if the investigation in education and pedagogy can to use the narrative, understood as a literary genre, which will allow the construction of knowledge with scientific validity and didactic strategy, in the processes of teaching and learning for the teacher.
\end{abstract}

\section{Keywords}

Truth, credibility, narrative, story, science, investigation, pedagogy, fiction 


\section{INTRODUCCIÓN}

Este documento surge en el contexto del Posdoctorado en "Ciencia y narrativa", dentro del convenio entre la Universidad de Córdoba (Argentina) y la Universidad Santo Tomás de Bogotá (Colombia), y es resultado de investigación en la línea de currículo y evaluación del Doctorado en Educación de la misma Universidad Santo Tomás y del Grupo de investigación "Investigación Educativa", categorizado en D por Colciencias.

Se propone investigar si la ciencia trabaja con relatos narrativos y si esta forma literaria puede ser útil para investigar en educación y pedagogía, ya que a primera vista pareciera que el discurso de la ciencia y el discurso narrativo fueran dos formas diferentes de adquirir conocimiento. Lo anterior se debe a que el discurso científico se rige, esencialmente, por la razón y la experiencia; en él, el elemento predominante es la objetividad sobre la subjetividad. Contrario al discurso de la literatura, el cuento, la poesía y otras formas narrativas, en los que la imaginación, los sentimientos y las emociones son los que tienen la prevalencia.

Jerome Bruner (1998) sostiene que existen dos modos de funcionamiento cognitivo, dos modalidades de pensamiento, y cada uno de ellos brinda diferentes maneras de ordenar la experiencia y de construir la realidad. Estas dos formas, aunque se complementan mutuamente, son irreductibles entre sí. Ambas difieren fundamentalmente en su manera de ser verificadas, aunque la pretensión de las dos es el convencimiento: los argumentos de la ciencia convencen por la verdad, pues su verificación se realiza gracias a procedimientos que permiten establecer una prueba formal o empírica; la otra forma, es decir, los relatos, convencen por su semejanza con la vida, en cuanto no establecen la verdad, sino la verosimilitud. Para Bruner, la estructura de un argumento lógico bien formulado difiere fundamentalmente de un relato bien construido. En palabras de Bruner (1998):

La aplicación imaginativa de la modalidad narrativa produce, en cambio, buenos relatos, obras dramáticas interesantes, crónicas históricas creíbles (aunque no necesariamente «verdaderas»). Se ocupa de las intenciones y acciones humanas y de las vicisitudes y consecuencias que marcan su transcurso. (...) La modalidad paradigmática, por lo contrario, trata de trascender lo particular buscando niveles de abstracción cada vez más altos, y al final rechazan en teoría todo valor explicativo en el que intervenga lo particular (p. 25).

Se infiere con facilidad que se trata de dos modos diferentes de construir conocimiento acerca de la realidad: uno verosímil, es decir, con apariencia o posibilidad de ser creído; y el otro verdadero. También el término "verdad" contiene diversos significados que van desde la ética y la moral, la metafísica o la filosofía, hasta la lógica, la ontología y la epistemología. Pero en este contexto, el significado es más que todo de tipo epistemológico, es decir, basado en la evidencia de la realidad, con justificación de certeza y validez, que interesa a la ciencia en cuanto pretende un conocimiento objetivo de las cosas. Sin embargo, aunque son dos modos distintos, también ambos contribuyen al conocimiento del ser humano, de su historia y de la naturaleza a partir de esas dos visiones y percepciones que la ciencia desarrolla cuando intenta comprender el mundo. A pesar de que estos dos conceptos no se identifican ni se oponen como si 
fuesen contradictorios, sí, por lo menos, se complementan, porque ambos pretenden incursionar en el campo de las ciencias sociales y humanas. Las dos modalidades de conocimiento se sirven del lenguaje, de la palabra $y$, en definitiva, del discurso, $y$ todo discurso, cualquiera sea su forma, es narrativo.

Así también los discursos de la ciencia son sistemas narrativos; son "leyenda", como bien los denomina Philip Kitcher (2001), porque describen y explican el conjunto de mitos, éxitos, fracasos y errores acerca del mundo y del hombre, acumulados durante siglos por la relación dialógica y al mismo tiempo dialéctica, entre el sujeto que conoce y el objeto de la realidad conocida.

Estos supuestos sobre las formas de relatar y describir la realidad permiten abordar la narrativa como una nueva forma alternativa de construir conocimiento, que se traslapa con el problema de la validez de las teorías construidas en el campo de la educación y la pedagogía. De aquí surgen, entonces, las siguientes preguntas: ¿qué papel cumple la narrativa en la ciencia? ¿La educación y la pedagogía pueden servirse de la narrativa en la construcción de su propio conocimiento? ¿Puede la narrativa ser aceptada por la comunidad académica como una estrategia epistemológica o metodológica para investigar en educación y pedagogía?

El desarrollo del tema comprende dos partes: una primera, consiste en la descripción del concepto de narrativa en el contexto de la ciencia. En ella se demuestra la forma como el conocimiento científico se ha servido de los relatos para construir y desarrollar aspectos importantes de su saber. Una segunda se centrará en un análisis acerca de la forma como la pedagogía construye sus conocimientos y la narrativa como una nueva alternativa literaria para exponer sus discursos en el contexto de la ciencia.

\section{EL CONCEPTO DE NARRATIVA Y}

\section{LA NARRATIVA DE LA CIENCIA}

\section{El concepto}

El término narrativa deriva del verbo latino narrare, que significa contar, relatar. El Diccionario de la Lengua Española (22a edición) hace referencia a esta palabra en el sentido de: "Contar, referir lo sucedido, o un hecho o una historia ficticios". A la vez, el término contar, deriva del latín computare, entre cuyas acepciones la más cercana al tema es la de "Referir un suceso, sea verdadero o fabuloso". Según este último significado, narrar algo puede entonces significar tanto un acontecimiento ficticio como verdadero.

En este mismo diccionario, el concepto de narrativa(vo), usado como adjetivo, significa: "Perteneciente o relativo a la narración. Género, estilo narrativo", y como sustantivo, afirma que es un "Género literario constituido por la novela, la novela corta y el cuento". Es decir que si nos atenemos a esta última acepción del diccionario, la narrativa solo se relacionaría con lo meramente ficticio, imaginario, con apariencia de verdad o apenas creíble, lo que equivale ciertamente a las características literarias de la novela y el cuento.

La narrativa, como género literario, engloba todo tipo de relatos que, para Goodman (citado en Bruner, 1998: 103), es una construcción de realidades en las que se "implica no un hacer con las manos sino con las mentes $\mathrm{o}$, más bien, con lenguajes u otros sistemas simbólicos". Señala además Bruner que 
la narración es una forma de pensamiento y una expresión de la visión del mundo de una determinada cultura. La narración cuenta historias o relatos de la vida cotidiana, pero vinculados con una epistemología de la subjetividad de quien escribe el relato.

\section{La narrativa de la ciencia}

Con todo, no es posible pensar que la literatura sea la única que tiene el privilegio de crear ficciones literarias. También la ciencia se ocupa de historias imaginarias que deleitan no solamente la mente de los niños, sino también de los adultos, especialmente cuando estos relatos han sido los precursores de muchos desarrollos científicos e inventos tecnológicos, al tiempo que han sido utilizados por los investigadores y científicos (desde diferentes perspectivas) como mecanismos para recolectar e interpretar datos (Coffey y Atkinson, 2003: 65).

De este modo, no todos los enunciados y las teorías de la ciencia se han construido sobre datos verídicos y la certeza de los hechos. Kuhn (1996) no duda en afirmar que la ciencia también trata de situaciones que no se han examinado en el laboratorio, ni siquiera podrían examinarse totalmente, así como tampoco tienen que darse necesariamente en la naturaleza. Se trata, en consecuencia, de "experimentos imaginarios" que, para Kuhn, "Lo menos que el historiador debe hacer es reconocerlos como instrumentos, en ocasiones muy potentes, para comprender más y mejor la naturaleza. No está nada claro, sin embargo, cómo es que pueden tener efectos tan significativos" (Kuhn, 1996: 263). Estos experimentos imaginarios de la ciencia describen fenómenos del mundo físico en un lenguaje narrativo, al estilo de al- gún cuento de hadas que podría servir para ser contado a algún niño antes de dormir.

En la ciencia moderna son muchos los ejemplos de narrativa con los que se busca dar explicaciones a fenómenos y acontecimientos de la naturaleza, de la vida o de la sociedad. Ernest Fischer, en su libro El gato de Schrödinger en el árbol de Mandelbrot. Una aproximación distinta al fascinante mundo de la ciencia (2010), trae a cuento, en forma amena y comprensible, algunos de los principales problemas de la filosofía y de la epistemología de la ciencia a través de un lenguaje simbólico y narrativo. Tomemos como ejemplo el mismo relato de "El gato de Schrödinger" que lleva el título del libro.

Fischer empieza con una cita de Rainer Kunz, autor de un libro infantil: "Sabe el hombre ir hasta la luna en un rato, pero no sabe hacer un gato"; y luego dice: "Todo y con ser bonita e importante, su frase no es del todo exacta, pues al menos un hombre sí logró hacer un gato". Se trata nada menos que del físico austriaco del siglo XX Erwin Schrödinger, y ese gato "anda rondando como un duende en nuestras cabezas" (Fischer, 2010: 15). Schrödinger no hace más que recrear en su mente un experimento con el cual consigue explicar el problema de la interacción y la medida de los átomos en la mecánica cuántica, imaginando un gato encerrado en una caja de acero, con un recipiente de cristal que contiene un gas letal, un martillo que en cualquier momento puede caer sobre el recipiente, romperlo y liberar el gas si un átomo radiactivo se desintegra y del que depende la suspensión del martillo. Puesto que nadie todavía ha podido observar en el interior de la caja, el gato está vivo y muerto a la vez. Alguien se preguntaría: ¿cómo es posible que pueda estar 
vivo y muerto a la vez? He ahí el misterio del cuento. En la naturaleza pueden darse esas posibilidades.

Aunque el experimento es meramente ficticio, ha sido, no obstante, objeto de toda clase de controversias y de las más diversas interpretaciones de científicos y filósofos. Sobre el tema se han escrito volúmenes de artículos y comentarios, ya que se plantea como un problema crucial de la mecánica cuántica, es decir, como una "teoría de las probabilidades" de la ciencia (Popper, 1982; van Fraassen, 1979). Mientras nadie haya abierto la caja en la que se encuentra encerrado el felino con el veneno mortal, no se puede saber tampoco si está vivo o muerto. Por tanto, para quien no haya observado su interior, el gato de Schrödinger está vivo y muerto. El científico no pretende otra cosa más que explicar, a través de este sencillo relato imaginario, un fenómeno que en el mundo de los quantos se conoce como superposición de estados (Fischer, 2010), el cual rompe con el principio lógico del imaginario común que pertenece al macro-mundo lógico de la contradicción aristotélica, según el cual una cosa no "puede ser y no ser" al mismo tiempo y bajo las mismas circunstancias (Met. L. IV, Г 1003a-1012b).

La superposición de estados es una consecuencia de la naturaleza ondulatoria de la materia y su aplicación a la descripción mecánico-cuántica de los sistemas físicos, que nos facilitan la comprensión, en el macro-mundo, del comportamiento de las partículas elementales y de los átomos, los cuales pertenecen al mundo micro. En otros términos, el experimento mezcla elementos de la física cuántica (la posibilidad de desintegración del átomo) con la realidad cotidiana del mundo macro-físico (la vida o la muerte del gato). Es esta la razón por la cual solamente cuando alguien como observador interactúa con el sistema, lo altera y rompe la superposición de los estados posibles, y por tanto puede darse cuenta de que para él existe solamente una de las dos posibilidades, a saber, si el gato está vivo o está muerto.

Parece un cuento de lo absurdo que se aleja del mundo real, en el sentido de lo que se pensaba hasta el siglo XX (y de lo que aún se piensa en la cotidianidad), que hoy presupone grandes desafíos, no solamente para la física, sino también para la filosofía de la ciencia, ya que nos permite obtener una concepción diferente de una realidad que dispone de inmensas posibilidades, pero que, sin embargo, está en función del observador y de lo que este observa.

Al igual que la narración del gato de Schrödinger, Fischer (2010) nos trae otros muchos ejemplos que ilustran la capacidad imaginativa y narrativa de los científicos que inventaban historias increíbles como elementos heurísticos o investigativos y que servían, a la vez, como mediaciones didácticas contadas en un lenguaje narrativo, como: “El demonio de Maxwell”, "El salto cuántico de Planck", "La herradura de Bohr", "El duende de Einstein", "El barreño de Newton", "El asno de Buridan", "La escoba de Brenner" y otras más que enriquecen el mundo de la fantasía científica.

El método y el lenguaje de las ciencias no se puede tomar como modelo único o ideal del conocimiento humano (Turón, 2001). Por el contrario, estos experimentos imaginarios ubican muchas de las teorías de la ciencia en el campo de la narrativa, que es utilizada en algunos casos como herramienta epistemológica o metodológica, pero también 
como recurso lingüístico, literario y pedagógico de enseñanza-aprendizaje, para dar explicaciones de los infinitos secretos de la naturaleza que de otra forma serían ininteligibles para los no especialistas en cuestiones de ciencia, al estilo de lo que representó el mito para las primitivas civilizaciones, la fábula y el cuento en la didáctica con los niños.

Los positivistas ortodoxos no reconocían esta forma literaria dentro del contexto científico, toda vez que reñía con ciertas reglas de objetividad y de neutralidad que debía poseer la ciencia. Sin embargo, hoy se trata de rescatar, a través de estas formas narrativas, aquella subjetividad del conocimiento excluida del mundo científico (Colom, 2002). No obstante que todavía seguimos convencidos de que la ciencia solamente construye conocimientos objetivos, tal como lo habían preconizado los científicos a partir de Newton y Galileo, prácticamente hasta mitad de siglo XX, momento en el que se ha logrado cambiar el paradigma y se ha rescatado nuevamente el papel del sujeto en el conocimiento científico.

En suma, la historia de la ciencia se ha construido sobre la ficción, la imaginación, la creatividad e, inclusive, lo pintoresco. Ian Crofton (2010), en su introducción a la Historia de la ciencia sin los trozos aburridos, nos pone de presente que:

Siguiendo estos senderos polvorientos [se refiere a la historia de la ciencia], uno se encuentra con todo tipo de personajes pintorescos: excéntricos-monstruos, charlatanes, bromistas e impostores, por no mencionar una plétora de experimentos locos, de anticipaciones asombrosas de acontecimientos futuros, ideas delirantes y especulaciones absurdas.
Los anales de la ciencia están repletos de teorías que deben más a un profundo deseo del proponente, razonamientos falsos, al fanatismo, al prejuicio y a la pura credulidad que a las pruebas empíricas (p. 7).

No significa esto que la narrativa sea una actividad de bromistas o charlatanes, sino que la ciencia no es tan objetiva como la pensamos y que muchos de los experimentos que nos cuenta la historia no son tan reales. Alexandre Koyré, en Estudios de historia del pensamiento científico (2000), en los capítulos que dedica a los experimentos de Galileo, sostiene que muchos de ellos nunca se llevaron a cabo; por ejemplo, los de la caída de los cuerpos desde la torre inclinada de Pisa. Sin embargo, todos recordamos cuando estudiábamos física en el bachillerato que nuestros profesores hacían referencia a los experimentos de Galileo para explicar el movimiento de los cuerpos, al mismo tiempo que nos convencían de que tales experimentos habían sido tan reales como los narraban los libros de ciencia. Pero si en verdad estos experimentos hubieran sido cruciales para la ciencia de la época, el mismo Galileo, por lo menos, los hubiera mencionado en alguno de sus escritos. La misma suerte se corre con los experimentos del movimiento de los cuerpos en el vacío que, para la época de Galileo, eran casi imposibles de realizar. Por otra parte, insiste Koyré (2000), los experimentos imaginarios han desempeñado un papel muy importante en la historia del pensamiento científico, todo porque en algunos casos son a menudo difíciles de realizar, ya que implican casi siempre equipos complejos y costosos. Estas son sus palabras:

Efectivamente es imposible producir una superficie plana que sea «verdaderamente» plana; o realizar una superfi- 
cie esférica que lo sea «realmente». No hay ni puede haber, in rerum natura, cuerpos perfectamente rígidos; como tampoco cuerpos perfectamente elásticos; no se puede realizar una medición perfectamente exacta. La perfección no es de este mundo; sin duda podemos acercarnos a ella, pero no podemos alcanzarla. Entre el dato empírico y el objeto teórico, queda siempre una distancia imposible de salvar.

Es entonces cuando la imaginación entra en escena. Alegremente suprime la separación. No se preocupa por las limitaciones que nos impone lo real. «Realiza» lo ideal e incluso lo imposible. Opera con objetos teóricamente perfectos y son estos objetos los que el experimento imaginario pone en juego (pp. 207-208).

En este mismo sentido, Kuhn argumenta que la función de los experimentos imaginarios es la de eliminar la confusión a la que siempre está sujeto el investigador cuando se halla frente a teorías que están dentro del campo de la verosimilitud. En otros términos, los experimentos imaginarios le ayudan al científico para llegar a leyes y teorías diferentes de las que había creído antes y, aunque, muchas veces, tales experimentos "no arrojan datos nuevos, están mucho más próximos a los de la experimentación real de lo que comúnmente se supone" (Kuhn, 1996: 265).

Estos casos de experimentos ficticios nos proporcionan una idea más de que la ciencia está hecha en parte de realidad y en parte de ficción o imaginación, por cuanto las teorías que se consideraron verdaderas durante siglos y que pretendían ser objetivas, porque se suponía que los hechos contenidos en sus narraciones y en sus enunciados ya habían sido probados, no eran más que meras especulaciones e imaginaciones de los científicos. Parece, pues, que la ciencia también opera con lo meramente verosímil. Así lo veremos a continuación con los argumentos de la ciencia ficción y su influjo en su desarrollo y en el de la tecnología.

\section{La ciencia ficción, otra forma de narrativa}

La ficción también ha sido uno de los grandes componentes de la ciencia, al menos como precursora de muchos experimentos y de innumerables inventos útiles a la humanidad. Conocemos uno de los grandes narradores de historias de ficción y precursor de algunos de los inventos más interesantes del mundo moderno, Jules Verne (1828-1905), quien en el siglo XIX con sus fantásticos relatos predijo con increíble exactitud la aparición de nuevas empresas y artefactos tecnológicos del siglo XX. Entre los inventos más conocidos preconizados por Verne, tenemos sin duda la televisión y las imágenes en movimiento, el helicóptero, el submarino, los viajes espaciales, el aire acondicionado, misiles dirigidos, solo para nombrar algunos. Basta con tener un recuerdo de aquellos libros que leíamos en nuestra infancia y juventud, cuando las imágenes de televisión todavía no habían invadido nuestra corteza cerebral: Cinco semanas en globo, Viaje al centro de la tierra, De la tierra a la luna, Veinte mil leguas de viaje submarino, La vuelta al mundo en 80 días, La isla misteriosa, Un capitán de quince años, escritos todos entre 1863 y 1878. La lectura de estas narraciones siempre nos transportó a mundos que hoy son reales, al tiempo que avivaban nuestra fantasía de adolescentes.

Todavía en 1994 salió a la luz otra de las más famosas novelas de Verne, París en el siglo XX, que había sido escrita en 1863 y 
se mantuvo oculta hasta 1989, cuando un bisnieto suyo encontró los manuscritos en una caja fuerte. Esta obra se publicó inicialmente en francés. La importancia está en que en ella se narra la vida de un joven dedicado a la literatura y a la poesía que, un siglo adelante, 1960, vive en un mundo de rascacielos de cristal, trenes de alta velocidad, automóviles movidos por sistemas de combustión interna, calculadoras y una red mundial de comunicaciones; y aunque vive en un mundo con todas las comodidades, no puede alcanzar la felicidad, por lo que termina su vida en una forma trágica ${ }^{1}$.

La lectura de este gran visionario no deja de asombrar a la humanidad por sus predicciones. Se sabe que Verne fue contemporáneo de científicos como Darwin, Mendel, Pasteur, Maxwell, Hertz, Humboldt, Planck, entre otros muchos. Tal vez estos influyeron en su imaginación de literato, pero también él influyó en su mente de científicos.

Un ejemplo más tomado de la ciencia ficción, pero ya no en el campo de las ciencias naturales sino en las ciencias sociales, es la novela del británico Aldous Huxley titulada Un mundo feliz (1976), publicada por primera vez en inglés en 1932. Esta obra describe un mundo imaginario sin sufrimiento físico, aunque sin ninguna iniciativa. La vida mecanizada origina una sociedad y un Estado en donde todo se resuelve por la ciencia. Los ciudadanos que no se hallan conformes con este Estado son tratados como enfermos. La trama se desarrolla en un Londres utópico, gigantesco y de atrevidas líneas futuristas que anticipa un desarrollo en tecnología reproductiva: cultivos humanos e

1 Disponible en http://biblioteca.vitanet.cl/colecciones/800/840/843/ paris.pdf hipnopedia, que cambian radicalmente la sociedad.

El mundo descrito por Huxley no deja de ser una utopía irónica, ya que la humanidad que vive en ese mundo en el que se ha erradicado la guerra, la pobreza y donde todos sus habitantes son permanentemente felices, experimenta una felicidad alcanzada sacrificando y eliminando valores como la familia, la diversidad cultural, el arte, la literatura, la religión, la filosofía y, sobre todo, la libertad del ser humano. En esta obra se perfila una satírica pintura de un porvenir no imposible, pues muchos de estos hechos que cuenta Huxley, ¿acaso no los estamos viviendo hoy?

Recordemos también que el cine y la televisión utilizan la narrativa de las imágenes en las que se han inspirado muchos adelantos científicos y tecnológicos. La serie televisiva de Star Trek, o Viaje a las estrellas, creada por Gene Roddenberry, ya desde 1966 dejaba vislumbrar un escenario de ciencia ficción que marcaría el rumbo de muchos jóvenes visionarios y soñadores, los que luego se convertirían en influyentes empresarios, prestigiosos científicos o calificados diseñadores de la tecnología del presente.

Esta serie inspiró las computadoras, los discos duros, las memorias y las tablets de tamaño reducido, así como muchas otras unidades con capacidad para almacenar enormes cantidades de datos y las pantallas gigantescas de televisión (plasma, LED, LCD, etc.). En la serie, el doctor McCoy podía realizar diagnósticos a través de imágenes utilizando mecanismos de ultrasonido, antecedentes de la resonancia magnética, cámaras de alta gama y otros tipos de diagnóstico por imágenes, tan útiles en la industria y en la medicina modernas. El teléfono 
móvil es uno de los más ingeniosos inventos nacidos en la serie Star Trek².

Imaginemos, por último, el gran número de películas y documentales de ciencia ficción que narran viajes hacia el pasado o el futuro, alienígenas que invaden el planeta, científicos que manipulan los cromosomas o el ADN, genes mutantes que crean seres monstruosos y atacan al propio ser humano, así como dinosaurios que invaden toda la tierra.

Quizás una de las mejores descripciones de lo que se entiende por ciencia ficción la podemos hallar en la Wikipedia de Internet (la enciclopedia libre), donde se resume la ciencia ficción como:

[...] un género especulativo que relata acontecimientos posibles desarrollados en un marco espacio-temporal puramente imaginario, cuya verosimilitud se fundamenta narrativamente en campos de las ciencias físicas, naturales y sociales. La acción puede girar en torno a un abanico grande de posibilidades (viajes interestelares, conquistas del espacio, consecuencias de una hecatombe terrestre o cósmica, evolución humana sobrevenida por mutaciones, evolución de los robots, realidad virtual, existencia de civilizaciones alienígenas, etc.). Esta acción puede tener lugar en tiempo pasado, presente o futuro, $\mathrm{o}$, incluso, en tiempos alternativos ajenos a la realidad conocida, y tener por escenarios espacios físicos (reales o imaginarios, terrestres o extraterrestres) o el espacio interno de la mente. Los personajes son igualmente diversos: a partir del patrón natural humano, recorre y explota modelos antropomórficos hasta desembocar en lo artificial de la creación humana (ro- bot, androide, cyborg) o en criaturas no antropomórficas ${ }^{3}$.

No hay duda de que una característica de la ciencia ficción es la coherencia con ciertas hipótesis de partida, que se diferencian de un realismo o de un subrealismo mágico. Por eso, para cerrar este espacio de la narrativa y la ciencia, es necesario tener presente que la ciencia ficción ha especulado sobre la antimateria, los agujeros negros, la nanotecnología, la comunicación instantánea, antes que lo haya hecho la propia ciencia. La ciencia ficción ha tomado muchos de sus argumentos y elementos de ambientación de conceptos o creaciones de la ciencia real, a la vez que esta también se inspira, frecuentemente, en elementos de la literatura ficticia para convertirlos en conceptos reales, hipótesis de trabajo u objetos tangibles, de cara al futuro científico y tecnológico.

\section{LA NARRATIVA COMO ESTRATEGIA LITERARIA PARA CONSTRUIR CONOCIMIENTO EN EDUCACIÓN Y PEDAGOGÍA}

Las ciencias sociales y humanas, en particular la educación y la pedagogía, se hallan hoy todavía en un dilema y se debaten entre la sospecha acerca de la validez de sus saberes y un cierto conformismo cuando ellas mismas confrontan sus teorías con otros tipos de saber, mucho más maduros, pero que han logrado construir un conocimiento riguroso y con mayor aceptación por la comunidad académica. Es esta una de las razones por las que los investigadores de la educación y la pedagogía, cuando se hallan ante problemas epistemológicos y metodológicos de la ciencia, ponen en duda

3 Recuperado el 19 de septiembre de 2011 desde <http://es. wikipedia. org/wiki/ciencia_ficci\%B3r>.

2 Ver <http://ciencia-ficcion.blogspot.com> 
la validez del conocimiento que se produce en el contexto natural de la escuela. A estas disciplinas se las suele tildar injustamente de "conocimiento débil" o "ciencias blandas", en contraposición a las mal llamadas "ciencias duras". Por esto quizás sea mejor utilizar los términos de "ciencias maduras" y "ciencias en construcción".

Si la ciencia en su sentido clásico y tradicional se vale de la narrativa y de la ficción como instrumentos lingüísticos y como estrategia heurística y didáctica, ¿por qué la pedagogía no puede hacerlo también? ¿Por qué a los investigadores de estas disciplinas, con cierta frecuencia e injustamente, se les exige que expongan sus argumentos bajo rígidos y sistemáticos procedimientos racionales en torno a la verdad de sus tesis, los cuales terminan, muchas veces, en falaces visos de objetividad?

Ante esta problemática, se pretende hallar una racionalidad científica que, bajo unos mismos fundamentos o enfoques epistemológicos y metodológicos de la ciencia clásica, pero mediante formas literarias del género narrativo, pueda alcanzar conocimientos válidos y pertinentes sobre educación y pedagogía. Esto no es obstáculo, según lo entienden Bolívar, Domingo y Fernández (2001), para que la investigación educativa se pueda valer de "un formato de argumentación narrativa y apoyarse -con algún grado de sistematicidad- en datos. La forma de presentación no determina ser una investigación, sino el modo como argumenta y justifica" (p. 115).

Es preciso aclarar que las ciencias de la educación y la pedagogía incluyen dos momentos en su metodología investigativa: la investigación en educación y la investigación de las prácticas pedagógicas o investi- gación en pedagogía. La primera se refiere a los aspectos macro de la educación como las políticas, los valores, la filosofía de la educación, la normatividad legal; mientras que la segunda, es decir, la investigación en pedagogía, se relaciona más bien con aquellos sucesos que ocurren en el aula de clase y la relación docente - estudiante, y el conocimiento que es enseñado y trasmitido $\mathrm{y}$ que suele plasmarse en el currículo. Herrera-González (2010), al respecto, nos ilustra con mayor claridad sobre esta distinción entre investigar en educación e investigar en pedagogía:

La investigación educativa, en este sentido, apunta a comprender de manera global los fenómenos educativos, por ejemplo, las relaciones existentes entre educación y economía o entre educación y procesos sociales macro, o la historia de la educación en las diferentes épocas. Por otro lado, la pedagogía constituye un tipo de saber que se ancla profundamente en la práctica. Es decir, la pedagogía como saber no se reduce a una teoría y, por ello, el sentido de la investigación pedagógica no es tanto una elaboración teórica dirigida a comprender de forma global la educación, sino el proceso dirigido a la explicitación de un saber pedagógico situado en unas condiciones sociohistóricas dadas. Puede decirse, entonces que la investigación educativa apunta a hacer lectura de la educación como un proceso social a escala macro mientras que la investigación pedagógica hace lectura de los procesos educativos a un nivel micro (p. 59)

Aunque es frecuente considerar la pedagogía como una práctica, no hay duda de que sobre las prácticas también se pueden construir discursos teóricos que inciden, orientan e iluminan de nuevo esa misma práctica; y aunque no todos los discursos son estrictamente científicos y no tienen un objeto 
único alrededor del cual se construyen proposiciones, ni tienen un orden deductivo de los conceptos (Zuluaga, 1999), sin embargo, sí es posible hacer ciencia y construir teorías acerca de las prácticas pedagógicas.

\section{El Grupo Federici de la Universidad Nacio-} nal de Colombia y el Movimiento Pedagógico del Magisterio en Colombia (que inició, este último, en la década de los ochenta), que son los que más han trabajado el concepto de pedagogía en Colombia, siempre la han concebido como "teoría reconstructiva" (Ríos, 2006). Así mismo, bajo este concepto, Olga Lucía Zuluaga y otros (2003: 36) dicen que "La pedagogía es la disciplina que conceptualiza, aplica y experimenta los conocimientos referentes a la enseñanza de los saberes específicos en las diferentes culturas".

Por tanto, en este contexto el término "teoría" encierra un significado especial, en cuanto, en primer lugar, el fin esencial de la ciencia es producir conocimiento y, en segundo lugar, este conocimiento se expresa literalmente en forma de teorías.

El concepto de pedagogía como "teoría reconstructiva" no es un concepto reduccionista que desconozca la complejidad, sino que, por el contrario, cuando hay que investigar en el campo pedagógico y construir sus teorías, no se puede desconocer su carácter interdisciplinario y transdisciplinario, $\mathrm{y}$ el influjo que ha recibido de otras ciencias como la psicología, la filosofía, la antropología, la economía, la administración, entre otras, así como sus objetos de estudio, como el currículo, la evaluación, la didáctica y los procesos de gestión de la escuela y de las demás instituciones educativas.
Sin embargo, cuando hablamos de pedagogía es necesario, además, considerarla en tres momentos significativos: la práctica, la praxis y la investigación.

En referencia a la práctica, es frecuente el uso del concepto como una técnica desarrollada por el docente, aplicable a los procesos de enseñanza-aprendizaje, particularmente relacionada con las didácticas, es decir, preparar y dictar la clase, utilizar las ayudas didácticas, construir pruebas para evaluar el aprendizaje y otras actividades más que, según Rafael Flórez Ochoa (1994), muchas veces terminan en un mero activismo. En las prácticas pedagógicas, los procesos organizativos de los maestros en el aula oscilan entre una acción técnica del currículo y una opción práctica y crítica del mismo. Pero también, la pedagogía y los pedagogos han incursionado en la praxis pedagógica, como una práctica reflexionada o una reflexión sobre las prácticas.

La praxis es un término que procede del griego clásico y significaba, originalmente, la acción de llevar a cabo algo; por tanto, se confundía con la práctica. Para Aristóteles, era un conjunto de "actividades prácticas" que realiza el ser humano y que se diferenciaba de la actividad teórica (Met. Lib. I, A 980a-993). En la filosofía moderna, el concepto de praxis tuvo una evolución, especialmente bajo el influjo de las corrientes marxistas. Así, la teoría crítica de la sociedad de la Escuela de Frankfurt (Adorno, 1973; Habermas, 2008) y su aplicación en la pedagogía crítica, adquirió otra connotación que se refiere a la unión dialéctica entre subjetividad y objetividad, teoría y práctica (Giroux, 2004). Paulo Freire (1967), por ejemplo, utiliza el término en el sentido de una práctica acompañada de reflexión o 
más bien una reflexión que se hace sobre la práctica. Estas son sus palabras en la Pedagogía del oprimido:

La afirmación tan conocida de Lenín: «No hay revolución sin teoría revolucionaria» significa precisamente que no hay revolución con verbalismo, ni tampoco con activismo, sino con praxis, por tanto, la reflexión y acción que incidan sobre las estructuras que tienen que ser transformadas (p. 164).

En general, suponemos que la praxis es el resultado de cambios progresivos o de conductas previas, lo que implica que será preciso contar con esquemas culturales, sociales e históricos muy complejos (Ferrater, 2004: 2877). La idea de praxis, entendida de este modo, corresponde muy de cerca con el significado en español de la expresión "hacer humano". Esta es la razón por la que, en educación y pedagogía, se define la praxis como la combinación de la teoría y la práctica de una actividad, pero con una intencionalidad que debe responder a los siguientes cuestionamientos: ¿qué?, ¿por qué? y ¿para qué? de lo que se enseña y aprende.

Bajo esta nueva concepción de la praxis, la reflexión de los maestros, plasmada en toda clase de textos (libros, artículos de revistas, protocolos), se convierte en insumo importante para hacer investigación documental y reconstruir la historia de la educación y la pedagogía. Estas reflexiones expresadas, por lo general, en un lenguaje narrativo, no responden propiamente a teorías científicas de la pedagogía y la educación.

Por tanto, hace falta otra mirada, mucho más profunda y sistemática, de la pedagogía, como lo es la de la investigación, con el objeto de construirla científicamente. Así, la pedagogía adquiere un carácter autónomo, pues existe la posibilidad de reconstruir sus conocimientos teórico-prácticos sobre los problemas específicos del currículo, la evaluación, la didáctica, la gestión y otras acciones pedagógicas, construyendo un objeto propio y un cuerpo organizado de doctrinas y enunciados teóricos.

Como la ciencia es una construcción artificializada (Echeverría, 1998), los conocimientos pedagógicos también se construyen colectivamente mediante procesos de investigación, de búsqueda, de discusión y debate entre los miembros de una comunidad que practican un mismo paradigma, como dice Kuhn (1992). Por tanto, estando entre las disciplinas más jóvenes, la pedagogía se halla en este proceso de construcción científica, y aunque todavía se discuta si es ciencia o no, esto "no impide definir su objeto de conocimiento, su estructura cognoscitiva, sus métodos de investigación, sus fronteras y relaciones con otras disciplinas y sus campos de aplicación" (Flórez y Tobón, 2001: 21).

Ahora bien, siendo la pedagogía una acción tan personal y humana, y tan cargada de valores, una de las mejores opciones para reescribir el conocimiento es el relato, porque, según afirman Bolívar, Domingo y Fernández (2001):

Como modo de conocimiento, el relato
capta la riqueza y detalle de los signifi-
cados en los asuntos humanos (motiva-
ciones, sentimientos, deseos o propósi-
tos), que no pueden ser expresados en
definiciones, enunciados factuales o
proposiciones abstractas, como el razo-
namiento lógico formal (p. 52).

La narrativa, entonces, se convierte en un instrumento lingüístico de expresión y de construcción teórica, logrando "emplear el 
lenguaje de una forma más abierta y plástica, huyendo de todo rigorismo reduccionista científico, teniendo en cuenta los «juegos del lenguaje» que descubrió Wittgenstein" (Turón, 2001: 2).

Sin embargo, hay que ser conscientes de que la narrativa no es una herramienta epistémica y metodológica, sino más bien un recurso lingüístico y literario muy valioso, no solamente para construir teorías científicas, sino, además, como estrategia didáctica para el desempeño por parte del docente de la doble función de la acción pedagógica: la "enseñabilidad de las disciplinas" y la "educabilidad del sujeto".

La primera es parte esencial del mismo estatuto epistemológico de la ciencia, por cuanto esta debe difundirse, acción que se realiza no solamente a través de toda clase de publicaciones y de otras formas de divulgación, sino y de manera especial, a través de los procesos de enseñanza-aprendizaje. Según Flórez Ochoa (1994) “La comunicabilidad del saber no es consecuencia sino condición de su producción, y cada disciplina podría caracterizarse por las formas de comunicación al interior de cada comunidad científica" (p. 77).

La segunda función de la pedagogía es la "educabilidad del sujeto" que, como una categoría del ser humano, significa la posibilidad que tiene cada sujeto de ser educable y perfectible; en otros términos, de ser formado. Gadamer (1997) utiliza el término alemán de Bildung en el sentido de formación. Así define el concepto: “La formación pasa a ser algo muy estrechamente vinculado al concepto de la cultura, y designa en primer lugar el modo específicamente humano de dar forma a las disposiciones y capacidades naturales del hombre" (p. 39).
También para Fermoso Estébanez (1991), "La educabilidad es la condición primordial del proceso educativo", y por tanto, para él, la educabilidad,

[...] significa la cualidad específicamente
humana o conjunto de disposiciones y ca-
pacidades del educando, básicamente de su
plasticidad y ductibilidad, que le permiten
recibir influencias y reaccionar ante ellas,
con lo que elabora nuevas estructuras es-
pirituales, que lo personalizan y socializan
(p. 235).

\section{Conclusiones}

Coffey y Atkinson (2003) señalan que en los años recientes los científicos sociales han ensayado diversas clases de representación literaria, entre ellas la narrativa. Por tanto, la ciencia, como conjunto de enunciados que describen, explican o interpretan la realidad, tanto natural como social y humana, se expresa a través de unas formas lingüísticas y de unos géneros literarios. La narrativa es uno de estos géneros. Pero estas formas lingüísticas son, a la vez, signos que deben estar ordenados en una estructura más o menos orgánica (sintaxis) y tener atribuida una función comunicativa (pragmática), que en el campo de la ciencia consiste en comunicar la verdad, es decir, transmitir información acerca de algún objeto del mundo físico o del mundo social y humano (semántica). En otros términos, el lenguaje adquiere una función representativa, en el sentido de que expresa la realidad de un mundo exterior en sus diferentes aspectos (Wittgenstein, 1994). Se llama también significativa porque permite transmitir, contar o decir algo de las cosas, de las cuales es símbolo y tiene para las personas un sentido especial. Si la narrativa cumple con estas características comunicativas, ¿por qué no puede valer para la ciencia? 
La narrativa funciona en pedagogía como representación de las acciones educativas, las cuales se vuelven significativas para los mismos sujetos. De esta manera, en el campo de la investigación pedagógica y como recurso puede ser de mucha utilidad para construir teorías que interpretan una realidad (hermenéutica), como en el caso, en primer lugar, de la narración biográfica (Bolívar, Domingo y Fernández, 2001), que desarrolla la historia de vida de los maestros; en segundo lugar, en estudios cruzados de historias de vida o relatos que nos permiten reflexionar sobre el contexto cultural y social de los profesores y el trabajo que realizan; y en tercer lugar, en el análisis global de fuentes documentales. En este sentido, Denzin (1989) "describe una narrativa como el relato de una secuencia de acontecimientos que tiene importancia para el narrador y su público" (Coffey y Atkinson, 2003: 65).

Por otra parte, la narrativa como género literario será también muy útil para el maestro en los procesos de enseñanza-aprendizaje para el trabajo con niños y adolescentes, de la misma manera que los científicos la utilizan para hacer comprender lo inexplicable de la ciencia. Si la Biblia utilizó este género para comunicar los misterios de un Dios, ¿por qué la pedagogía no puede hacer lo mismo para enseñar y transmitir el conocimiento?

\section{REFERENCIAS}

Adorno, T. W. (1973). Consignas. Buenos Aires: Amorrortu Editores.

Aristóteles. (1992). Metafísica. Bogotá: Ediciones Universales.

Bolívar, A. Domingo, J. y Fernández, M. (2001). La investigación biográfico-narra- tiva en educación. Enfoque y metodología. Madrid: La Muralla.

Bruner, J. (1998). Realidad mental y mundos posibles (4⿳亠丷⿵冂丶 . reimp.). Barcelona: Gedisa.

Coffey, A. y Atkinson, P. (2003). Encontrar el sentido a los datos cualitativos. Estrategias complementarias de investigación. Medellín: Editorial Universidad de Antioquia.

Colom, A. (2002). La (de)construcción del conocimiento pedagógico. Nuevas perspectivas en teoría de la educación. Barcelona: Paidós.

Crofton, I. (2011). Historia de la ciencia sin los trozos aburridos. Curiosidades y locos experimentos. Barcelona: Ariel.

Echeverría, J. (1998). Filosofía de la ciencia (2ª ed.). Madrid: Akal.

Fermoso Estébanez, P. (1991). Teoría de la educación. México: Trillas.

Ferrater Mora, J. (2004). Diccionario de filosofía (3 ${ }^{\text {a }}$. reimp.), 4 tomos. Barcelona: Ariel.

Fischer, E. P. (2010). El gato de Schrödinger en el árbol de Mandelbrot. Una aproximación distinta al fascinante mundo de la ciencia, (2ª . ed.). Barcelona: Crítica.

Flórez Ochoa, R. (1994). Hacia una pedagogía del conocimiento. Bogotá: McGraw-Hill.

Flórez Ochoa, R., y Tobón Restrepo, A. (2001). Investigación educativa y pedagógica. Bogotá: McGraw-Hill.

Fraassen van, B.C. (1979). La imagen de la ciencia. México: Paidós.

Freire, P. (1967). Pedagogía del oprimido. Bogotá: Editorial América Latina.

Gadamer, H-G. (1997). Verdad y método (7a․ ed.). Salamanca: Sígueme.

Giroux, H. (2004). Teoría y resistencia en educación (6 $6^{\mathrm{a}}$. ed.). México: Siglo XXI Editores. 
Habermas, J. (2008). Teoría y praxis. Estudios de filosofía social (5⿳亠丷. ed.). Madrid: Tecnos.

Herrera-González, J.D. (2010, julio-diciembre). La formación de docentes investigadores: el estatuto científico de la investigación pedagógica. Revista $\mathrm{Ma}$ gistro, 3 (5), 53-62.

Huxley, A. (1976). Un mundo feliz. Barcelona: Plaza \& Janés.

Kitcher, P. (2001). El avance de la ciencia. México: Universidad Nacional Autónoma de México.

Koyré, A. (2000). Estudios de historia del pensamiento científico (15a. ed.). México: Siglo XXI Editores.

Kuhn, T.S. (1992). La estructura de las revoluciones científicas (1 ${ }^{a}$. reimp.). Bogotá: Fondo de Cultura Económica.

Kuhn, T.S. (1977/1996). La tensión esencial. Estudios selectos sobre la tradición y el cambio en el ámbito de la ciencia (2a․ reimp.). México: Fondo de Cultura Económica.
Popper, K.R. (1982). La lógica de la investigación científica (6 ${ }^{\mathrm{a}}$. reimp.). Madrid: Tecnos.

Ríos Beltrán, R. (2006, enero-abril). De la pedagogía a las ciencias de la educación: una lectura desde el saber pedagógico colombiano. Revista Educación y Pedagogía, XVIII (44), 11-31.

Turón Mejías, M.A. (2001, septiembre). Aprender a leer desde lo narrativo. Revista electrónica Aparte Rei, 17. Recuperado el 1 de octubre de 2011 desde http:// serbal.pntic.mec.es/AParteRei/

Wittgenstein, L. (1994). Tractatus Logico-Philosophicus. Barcelona: Altaya.

Zuluaga Garcés, O.L. (1999). Pedagogía e historia. La historicidad de la pedagogía. La enseñanza, un objeto de saber. Bogotá: Anthropos.

Zuluaga O.L., Echeverri, A., Martínez B., A., Quiceno H., Sáenz, J. y Álvarez G., A. (2003). Pedagogía y epistemología. Bogotá: Magisterio. 